\title{
LA IMAGEN DEL TERRORISTA EN LA NOVELA ESPAÑOLA ACTUAL
}

\author{
$\mathrm{M}^{\mathrm{a}}$ DOLORES ALONSO ReY \\ Universidad de Angers (Francia)
}

\begin{abstract}
El fenómeno de la violencia política en general y del terrorismo en particular es estudiado con ahínco por las ciencias sociales como muestra la abundantísima bibliografía que existe sobre este tema. Llama la atención observar, por un lado, el deseo de ciertos investigadores españoles de que la creación estética ${ }^{1}$ se ocupe hoy del terrorismo como lo hizo ayer ${ }^{2} \mathrm{y}$, por otro, el desánimo de los que constatan la ausencia de dicho tema en las artes. Esta ausencia se produce a pesar de que la industria cultural difunde la violencia tan masivamente que llega a banalizarla y a legitimarla³. En el País Vasco, Mikel Iriondo señala que no existe reflexión sobre el terrorismo en los productos
\end{abstract}

\footnotetext{
1 «El arte es la manera de ligar el sentimiento con la razón para anudar nuevas e insospechadas experiencias de vida. El arte es capaz de crear alternativas a aquello que en este momento provoca un dolor incomprensible para quienes han crecido y se han formado intelectualmente con los valores democráticos.»F. J. Ugarte Pérez, «El terrorista. Alienación del héroe romántico», Leviatán: Revista de hechos e ideas, n 65, 1996, p. 22.

2 A. Glucksmann, Dostoïevski à Manhattan, Paris, Robert Laffont, 2002. En este estudio el pensador hace un elogio a literatos del S. XIX, como Puschkin, Chejov, Dostoïevski, Flaubert, cuyas obras denuncian y anticipan la amenaza del nihilismo.

${ }^{3} \mathrm{~V}$. Bozal, «Hipótesis para una investigación » proyecto de la UCM Representación de la violencia y el Mal en la cultura y el arte contemporáneo. www.ucm.es/info/varte/actividades/reunión
} 
culturales en euskera ya que el mundo nacionalista, que lo aplaude, es su único consumidor 4 . Pero la misma ausencia se constata, por ejemplo, en el teatro escrito en español para consumo no nacionalista. En este caso, no parece posible aducir una explicación convincente sobre tal ausencia en un género que suele calificarse de realista ${ }^{5}$. En cambio, en la novela alguna cabida se le ha dado.

Por la escasez de estudios sobre el asunto y por la importancia del mismo en nuestro presente, hemos analizado una serie de relatos con el propósito de mostrar cómo se trata este tema en la ficción.

Sin ánimo de ser exhaustivos, hemos constituído un corpus formado por diecisiete relatos 6, en el que incluímos la novela traducida del vascuence Grande Place de Onaindía, dado el pasado etarra del autor. Este corpus puede clasificarse según diferentes criterios. Según la historia del terrorismo, tendríamos novelas con terroristas anarquistas (El atentado, La verdad sobre el caso Savolta), con comando de resistentes para cometer magnicidio contra Franco ( $\mathrm{La}$ noche española), con grupos de ultraizquierda en la democracia (El mensajero, Destruyan a Anderson) o con etarras, todas las demás. Se podría clasificar también temáticamente: novelas sobre magnicidios (La noche española, Kilómetro cero), sobre secuestros (Lectura insólita de El Capital, Una belleza convulsa), novelas de terrorista que duda (Comandos vascos, Y Dios en la última playa, Grande Place, Gudari Gálvez), novelas de víctimas vengativas (La costumbre de morir, Vivir para matar).

Es más arduo clasificarlas atendiendo a su género. Un buen número de ellas se emparentan con la novela negra, modalidad que, junto con la novelaenigma, constituye el popular género de la novela criminal 7 , tan cultivado en

\footnotetext{
4 « ...las manifestaciones artísticas que abordan la violencia terrorista que nos atenaza desde hace casi 40 años, son casi inexistentes » M. Iriondo, « Arte y violencia en el país Vasco » proyecto de la UCM Representación de la violencia y el Mal en la cultura y el arte contemporáneo. www.ucm.es/info/varte/actividades/reunión2002/MIRIONDO.pdf

5 «...la presencia del terrorismo como motivo dramático ha sido nula en nuestros escenarios»,

P. Ruiz Pérez, «El drama del terrorismo en La emperatriz de los helados de Luis Riaza», Revista de literatura, Tomo 58, n 116, 1996, p. 454.

6 Tomás Salvador, El atentado (1960) ; Raúl Guerra Garrido, Lectura insólita de El Capital (1976) y La costumbre de morir (1981); Ricardo Lechuga, Nubarrones (1979); Manuel Villar Raso, Comandos vascos (1980); Cristóbal Zaragoza, Y Dios en la última playa (1981); Leopoldo Azancot, La noche española (1981) ; Mario Onaindia, Grande Place (1982); Jorge M. Reverte, El mensajero (1982) y Gudari Gálvez (2005) ; Eduardo Mendoza, La verdad sobre el caso Savolta (1983) ; Fernando Martínez Laínez, Destruyan a Anderson (1983) ; Eugenio Ibarzábal, La trampa (1987) ; Azahara Larra Servet, Extranjeros en su país (1992) ; Jesús Cacho, Kilómetro cero (1996) ; José Manuel Fajardo, Una belleza convulsa (2001) ; Alfonso Rojo, Matar para vivir (2002).

${ }^{7}$ En la novela negra predomina una búsqueda dinámica del criminal, lo que la une a la novela de aventuras, mientras que en la novela-enigma la búsqueda es eminentemente racional y lógica, de manera que entre autor y lector se establece un enfrentamiento lúdico en la resolución del
} 
España a partir de 1975. En él la estructura básica de la acción se reduce a tres unidades : Crimen - Búsqueda/No búsqueda - Localización/No localización. El tiempo de la acción es el presente del lector y ésta se ubica en un ámbito urbano. Si el protagonista es el investigador, representante de la ley o profesional liberal, encarna la figura del anti-héroe. Si es el delincuente, bien responde al mito del "delincuente-honrado" con su particular moral, bien actúa en su propio beneficio o bien, como autor del delito, es perseguido por la Justicia8.

En novelas como Destruyan a Anderson o El mensajero, los antagonistas son unos terroristas de ultraizquierda que atentan en Madrid al albor de la democracia. Los protagonistas investigadores, funcionarios de policía, restablecerán el orden inicialmente perturbado capturando a los terroristas. En El atentado, novela ambientada en el Madrid de Alfonso XIII, unos anarquistas atentarán contra un gobernador, antiguo militar. Este, por honor, rechaza la escolta que le proporciona el jefe superior de policía, quien aniquila al comando tras el crimen. Los investigadores juegan un papel secundario porque lo que interesa es mostrar el estado de ánimo de víctima y terroristas ante el acto de morir y matar. La modalidad de investigador privado aparece en Gudari Gálvez. La misión del periodista consiste en evitar que un terrorista neófito cometa lo irreparable. El mito del "delincuente-honrado" aplicado al terrorismo aparece en Vivir para matar cuyo protagonista, que es un veterano de la lucha antiterrorista, se convierte en un asesino de etarras a sueldo. En Kilómetro cero, a un antiguo infiltrado en ETA sus antiguos mandos -implicados en los Gal- le encargan asesinar al presidente del gobierno, Felipe González. En cambio el protagonista de La costumbre de morir sería el delincuente: un joven que asesina al asesino etarra de su padre, guardia civil. Las demás novelas son de difícil clasificación. Se ha caracterizado La trampa como una novela policíaca de política-ficción ${ }^{9}$ : un gobierno de derechas acaba con ETA y convoca un referendum sobre la autodeterminación. Ganan el no y la abstención. La verdad sobre el caso Savolta presenta concomitancias con la novela-enigma y relatos como Comandos vascos, Y Dios en la última playa, Grande Place, Lectura insólita del capital, Una belleza convulsa serían calificadas de «novelas de terroristas». Son relatos protagonizados por terroristas o por víctimas de un secuestro en los que importa la introspección psicológica de los protagonistas.

No determinaremos si estamos ante un género o subgénero de «novelas de terroristas », estos relatos nos interesan porque nuestro propósito es estudiar

misterio propuesto por el autor. Vid. José R. Valles Calatrava, La novela criminal española, Granda, 1991.

8 J. R. Valles Calatrava, op. cit.

${ }^{9} \mathrm{~A}$. Buschmann, « La novela policíaca española. Cambio social reflejado en un género popular » en Abriendo caminos. La literatura española desde 1975, eds. Dieter Ingenschay y Hans-Jörg Neuschäfer, Barcelona, Editorial Lumen, 1994, pp. 245-254. 
los terroristas de novela ${ }^{10}$, esto es, la imagen del terrorista que se transmite en la ficción.

Las novelas que nos ocupan tocan el tema del terrorismo. Aunque su definición no es simple, seguimos a P. Wilkinson que lo define como intimidación coactiva ${ }^{11}$ sustentada en una teoría, próxima a la tortura, según la cual los individuos amenazados desistirán de sus principios para salvar la vida y, una vez aterrorizada la sociedad, ésta se someterá. El terrorista ha sido caracterizado como el heredero alienado del héroe romántico, fruto de las teorías de Hegel, Marx, el tradicionalismo y el nacionalismo. El joven que sigue su ley de corazón ${ }^{12}$ contra todos se nos presenta en estos relatos como miembro del grupo en el que se integra y como ser individual ${ }^{13}$. Lo analizaremos en primer lugar desde estas dos perspectivas a las que añadiremos el estudio de la figura del ex-terrorista más la visión que del terrorista tienen las víctimas.

No sólo el discurso ideológico o el ámbito social o cultural empujan a un individuo a la acción violenta terrorista sino también la seducción, primero, y la presión, después, que el grupo ejerce sobre él. Sobre éste influye la clandestinidad, que tiene sus propias reglas y efectos ${ }^{14}$, el deber de someterse a la autoridad de la jerarquía, el mimetismo entre los miembros del comando y el desarrollo de un pensamiento grupal (groupthink)15. Las relaciones y conflictos que se establecen en el seno de los comandos terroristas así como los tipos humanos que los integran han interesado especialmente a los novelistas. Examinaremos, pues, esos microcosmos centrándonos, primero, en los anarquistas, a continuación, en los comandos de ultraizquierda y, por último, en los etarras. Haremos hincapié en la figura del líder, sus subordinados, especialmente en las mujeres, y en el tipo de conflictos que se originan.

Los cuatro anarquistas que forman el grupo de acción directa de la Federación Ibérica Proletaria en El atentado son pesentados como seres individuales sobre cuya humanidad se insiste. Son cuatro hombres de diferentes edades, niveles de instrucción y motivación: el estudiante de filosofía, siempre

${ }_{10}$ Hacemos alusión al conocido estudio de J. A. Blas, La novela de espías y los espías de novela, Barcelona, Montesinos, 1991.

11 «It is the systematic use of murder and destruction, and the threat of murder and destuction in order to terrorise individuals, groups, communities or goverments into conceding to the terrorist' political demands» P. Wilkinson, Terrorism and the Liberal State, New York Unyversity Press, Nueva York, 1986, p. 51.

12 F. J. Ugarte Pérez, «El terrorista. Alienación del héroe romántico », Leviatán : Revista de hechos e ideas, $\mathrm{n}^{\circ} 65,1996, \mathrm{pp} .15-22$.

13 E. Echeburua, P. de Corral «Raíces psicológicas del fanatismo político» en Análisis y modificación de conducta, Vol. 30, No. 130, 2004, pp. 161-176.

14 Sobre la precariedad de la vida clandestina Vid. P. Moa, De un tiempo y un país. La izquierda violenta (1968-1978), Madrid, Ediciones Encuentro, 2002.

${ }^{15}$ X. Crettiez, Violence et Nationalisme, Paris, Odile Jacob, 2006, p.196. 
acompañado del libro de su mentor ideológico Kropotkin ${ }^{16}$, que se enamora de la chica del jefe del grupo, antiguo profesor; el baturro enfermo que ama la acción y Mandarino, que sueña con ser dueño de una taberna. Este heterogéneo e indisciplinado grupúsculo se verá confinado en un sótano insalubre para vigilar y asesinar al gobernador. Allí se enfrentarán al dolor de la enfermedad, tendrán compasión por el enfermo, sentirán el miedo a la muerte y el miedo a matar, envidiarán a su víctima al tiempo que se pondrán en su lugar ; sufrirán de amor y de celos, soñarán, dudarán y cuestionarán la ideología a la que sirven denunciando la colisión entre los ideales y la realidad... El estudiante siempre está dispuesto a exponer la teoría y a justificar su rebelión y el crimen para incitar a las masas a la revolución :

[porque] su excelencia representa la autoridad, una de sus bases[de la sociedad] Otra es el capital y, una tercera, el equilibrio social llamado orden público[...] porque ellos empezaron con la violencia social [...] Fueron violentos con sólo « ser »-

Los otros miembros le conminan a cesar el adoctrinamiento. E incluso cuestionan tales razones :

¿es posible que estemos equivocados ?¿No será retórica pura todo eso ?

Tal independencia y disparidad de criterios se pondrá de manifiesto, justo antes del asesinato, en el reparto del dinero que debe servirles para escapar. El estudiante no soporta enfrentarse al envés crematístico del mundo de sus ideas y pasar por un mercenario. Asesinar con el dinero en el bolsillo es para él un acto impuro que contrasta tanto con el sentido práctico del futuro tabernero, que exige una mayor cantidad para exiliarse en Francia, como con el escepticismo revolucionario del enfermo que explica las razones del pago en ese momento :

porque de cada diez que reciben instrucciones y dinero, nueve guardan los cuartos y olvidan el trabajo.

En cambio en La verdad sobre el caso Savolta, se ofrece una visión opuesta : los anarquistas, estrechamente relacionados con el mundo obrero, aparecen como un grupo sin fisuras, carecen de espesor humano, como si se tratara de un tipo sociológico. Forman un todo en la acción -tiroteo en el teatro para eliminar

16 Teórico ruso anarquista (1842-1921) defensor de las acciones violentas (la propaganda por el acto) e incitador a la preparación de la revolución como medio para despertar la conciencia popular. Vid. G. Chaliand y A. Blin, Histoire du terrorisme, Paris, Bayard, 2004, p. 128. 
al dueño de la fábrica en huelga - y cuando son arrestados. Desempeñan el papel de perdedores - son los que cuentan con más bajas en el atentado del teatro- y de cabezas de turco. Les endosarán la autoría de crímenes que han cometido aventureros instalados en una fraudulenta burguesía catalana. La visión estereotipada de estos terroristas la tenemos a través del protagonista :

Hombres barbados, cejijuntos y graves, ataviados con faja, blusón y gorra, hechos a la espera callada tras una barricada de muebles destartalados, tras los barrotes de una celda de Montjuïc[...] Hombres que aguardan agazapados, estallaban en furia y eran ejecutados al amanecer.

Visión que contrasta con la que tiene de sus compañeras femeninas, unas mujeres joviales, entregadas y espontáneas que aprovechan la huelga general de Cataluña para predicar del amor libre :

Pude comprobar que no cobraban por ejercer su apostolado, si bien aceptaban comida, vino, tabaco y algún obsequio de poco valor (un pañuelo, unas medias[...], un retrato de Bakunin) [...] las fui catalogando sucesivamente como locas, farsantes, chifladas y santas a su manera.

El modelo organizativo de los grupos terroristas de ultraizquierda y etnonacionalistas-izquierdistas, como ETA, deriva de las exigencias de la clandestinidad y de la búsqueda de eficacia terrorista. Se basa en el centralismo y en la jerarquización. A los militantes, que ni participan en la toma de decisiones ni en la renovación de dirigentes, se les exige una entrega total a la causa ${ }^{17}$. En las ficciones que nos ocupan, los comandos presentan una estructura jerarquizada en cuya cúspide se encuentra un jefe que actúa como único nexo de unión entre los componentes y los dirigentes de la organización. El jefe encarna la organización, proporciona información e instrucciones para actuar, además de ser el garante del orden interno. Exige a sus subordinados obediencia, sumisión y disciplina militar. Un halo de misterio le rodea. Aparece como un ser opaco, distante y duro. En El mensajero, Inés describe así a su jefe, Enrique:

Su entrega absoluta al trabajo le convertían en un ser casi omnisciente[...] tenía algo de inhumano, de inasequible a las debilidades ajenas

El mismo esquema se reproduce en las relaciones entre Enrique y Leonor, su contacto con la dirección del partido. Una mujer de clase social

17 F. Domínguez, Dentro de ETA, Madrid, Aguilar, 2002, p. 271. 
elevada - maneras y expresión distinguidas, belleza perfecta- que desestabiliza a Enrique a causa de la distancia jerárquica y social que los separa y del contraste que se produce entre la imagen que él tiene de su partido y de su militancia y ella .

En las novelas sobre ETA, Comandos vascos e $Y$ Dios..., el jefe, un hombre maduro, es un ejemplo para el joven neófito : un modelo de perfección. Pero ante todo es un enigma ${ }^{18}$ que debe resolver. El recién llegado no conoce su nombre -A. y Papadoc, respectivamente - ni su pasado. Examina sus acciones, palabras, comportamientos a partir de los cuales elabora hipótesis con las que construir su retrato. Y éste es el de un superhombre o el de un hombre casi deshumanizado, antiguo religioso probablemente ${ }^{19}$ :

Tengo la impresión de que pasó por la Iglesia con el fin de estudiar su organización y traspasar a la nuestra su carisma( a menudo dice que el impulso revolucionario es en esencia religioso) (Comandos vascos)

Se presenta como una máquina de matar instruída, fría, cerebral, hecha al dolor físico, a la soledad afectiva, al disfraz, carente de compasión y de piedad. Su gran preparación intelectual -Papadoc lee en latín a los clásicos-, su resistencia y su destreza en la acción asesina lo convierten en una nueva versión del hombre de letras y de armas. Su personalidad desestabiliza al aprendiz. Para éste, buscar su debilidad se convierte en un objetivo. En Y Dios..., el disciplinado protagonista, aunque no se enfrenta a su jefe, se crece moralmente, se libera de su dependencia, verbalizando en un monólogo interior el envés del personaje: un hombre que duda de lo que hace y predica. Como si fuera un remedo maligno del cura unamuniano de San Martín Bueno, mártir:

Todo en orden, excepto tu fe en los métodos que utilizas para sembrar el terror entre tus conciudadanos. Pero hay algo más, Papadoc. [...]¿qué me dices del temor de Dios? Es tu tendón de Aquiles, Papadoc. Te lo he notado en la iglesia. De rodillas eras un hombre derrotado, pero un hombre, que es lo que te niegas a ser. Lástima me das, Papadoc.

Frente al líder y al protagonista, se encuentran los otros miembros del comando, que se caracterizan en principio por su ausencia de dudas. Son

\footnotetext{
18 Los paralelismos entre estos dos relatos son numerosos : la forma autobiográfica, la trayectoria del terrorista, sus relaciones afectivas -padres, novia-, el retrato del jefe, la mujer terrorista... Tanto es así que M. Villar Raso acusó a Zaragoza de plagio. Vid. ABC, Madrid, 14-IX-1981.

19 Vid. J. Bastante, Los curas de ETA : la iglesia vasca entre la cruz y la ikurriña, Madrid, La Esfera de los libros, 2004 . Vid «A Dios rogando y con las pistolas matando » en J. Díaz Herrera, I. Durán, ETA, el saqueo de Euskadi, Barcelona, Planeta , 2002.
} 
sujetos que matan con frialdad y que carecen de escrúpulos o remordimientos. Presentan algunas características de la personalidad del terrorista. Según los especialistas, los terroristas son individuos que poseen un pensamiento dicotómico, maniqueo. Han sido desconectados moralmente, es decir, no se autocensuran $^{20}$. El protagonista de $Y$ Dios... analiza, lúcido, su propia desconexión moral - «... la víctima también es un hermano mío y sin embargo no dudo en disparar o poner el trozo de chicle bajo el coche »- e incluso la «trasmutación» del terrorista cuando actúa. Este sufre una serie de trasformaciones físicas y mentales que dan cuenta de su personalidad escindida $^{21}$ :

Yo sé cuándo va a hacerlo por la forma de mirarme. Sin verme. Está en otra parte. No es él. [...]Suda angustia y miedo.[...] Luego, cuando ha realizado el trabajo[...] sus ojos me ven, tiene la frente limpia, sabe sonreír, y si entramos en una cafetería le pone cortesmente la silla a Gayolita y bromea con el camarero.

Para algunos individuos la violencia deja de ser un medio y se convierte en un fin. Experimentan en ella el goce de la transgresión y la viven como una afirmación vitalista frente al « tedio de la democracia »22. Esta impresión recibe del grupo un agente doble, en la novela Kilómetro cero :

No hablaban de otra cosa. [...] no pensaban más que en matar. Sólo importaba matar. Todo lo que oliera a uniforme era objetivo de sus pistolas.[...] Juan no habló nunca con ningún etarra que dijera éste es buena persona, a éste no lo vamos a matar...

En Y Dios... Zin disfruta matando. A lo largo de todo el relato se insiste en considerar al terrorismo como una adicción, como una droga, y al terrorista como un autómata alienado, de crueldad gratuita a veces, que ronda la locura. El líder mismo, Papadoc, acaba confesándoselo al novicio :

Se llega a un momento en que ya no hay causa. Hay curiosidad por saber cómo muere la víctima. De ver cómo muere. Verlo, y al mismo tiempo, aspirar el olor de la sangre, un tufillo que acaba por volver loco a uno[...] compensa todo el sufrimiento.

\footnotetext{
20 F. Reinares Nestares, «Perfil del terrorista » en J. Sanmartín (coord.) El laberinto de la violencia : causas, tipos, efectos, Barcelona, Ariel, 2004, pp. 283-290.

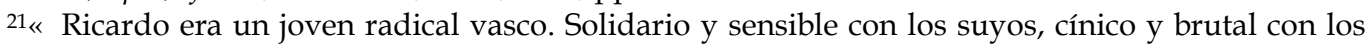
que él consideraba enemigos, era un buen ejemplo de ese ser esquizofrénico capaz de asesinar por la mañana en aras de un principio y emocionarse por la tarde » La tampa

22 Vid. «Violence nationaliste et réenchentement » en X. Crettiez, op. cit., pp. 79-124.
} 
La sumisión total a la organización la encarna el personaje de Mostachos, animalizado física - « Gruñe. Vuelve a enseñar los colmillos y me doy perfecta cuenta de que no trata de asustarme sino que en realidad es así, una fiera »- y moralmente : duerme en el suelo junto al jefe como muestra de su fidelidad perruna. En Comandos vascos, el protagonista, al que su iniciativa individual le lleva a querer escribir una novela, se ve obligado a pedir autorización a la organización, momento en el que descubre la visión utilitaria y animalizada que de él tiene su jerarquía :

Para el burú eres una larva automática y entontecida, ¿de qué te asombras? (son las reglas inquebrantables del juego en el que andas metido y no te las puedes saltar), que se alimenta de la comida que le ponen delante y de ideas que endurecen el cerebro, ¿podrás sobrevivir?

A diferencia de los comandos anarquistas, los comandos terroristas modernos se caracterizan por su hetereogenidad socioeconómica y por la presencia femenina.

En los menesteres asesinos, la mujer ha alcanzado la igualdad con el hombre, como han demostrado militantes y dirigentes femeninas de ETA ${ }^{23} y$ de grupos de ultraizquierda alemanes e italianos. Esta presencia suele explicarse por el hecho de que ciertos movimientos feministas se hayan impregnado de ideologías violentas ${ }^{24}$. La clandestinidad provoca que entre los miembros masculinos y femeninos se establezcan relaciones amorosas endogámicas ${ }^{25}$. En las novelas analizadas, las terroristas ocupan un papel importante a pesar de que su presencia sea contestada por algunos miembros :

una mujer está perfecta empuñando el cuchillo de cirujano, con un arma en la mano ensucia la guerra (Comandos vascos)

Las mujeres, por un lado, hacen gala de su alta cualificación en la administración de la muerte al prójimo ${ }^{26} \mathrm{y}$, por otro, de su sexualidad libremente asumida. Encarnan el sexo y la muerte, en una nueva versión del eros y el tánatos vividos apasionadamente con urgencia. Se trata de una sexualidad liberada de todo vínculo afectivo y moral, centrada en la búsqueda

${ }_{23}$ M. Antolín, Mujeres de ETA. Piel de serpiente, Madrid, Temas de hoy, 2002.

24 F. Alonso-Fernández, Psicología del terrorismo, Masson-Salvat, 1994, p.263.

25 F. Domínguez, op. cit., pp. 36-38.

26 Sobre la abultada presencia de mujeres asesinas en la novela actual española Vid. S. Godsland, «Mujeres que matan : violencia femenina y transgresión social en la novela criminal femenina española », España contemporánea : Revista de literatura y cultura, 2002, Tomo 15, № 2, pp. 7-22. 
del placer o concebida como mera actividad fisiológica. «Un alivio de la neurosis[...] un remedio para dormir mejor » sostiene Anderson, un terrorista vitalista y nihilista a la vez para quien el sexo se integra en el proyecto revolucionario :

La libertad sexual no tiene objeto porque no tiene límites, pero a condición de que no pierda el cabo de la revolución, porque en ese mismo momento está engendrando contrarrevolución.

Junto a la imagen de la mujer liberada sexualmente convive la de la mujer como objeto sexual. Así de crudamente se describe una ex-etarra en Gudari Gálvez :

Me usaba como si yo fuera un lugar de descarga de sus ímpetus. Luego más tarde, supe que usaba también a otras. Las mujeres no éramos mucho allí, ya sabes.

En Comandos vascos, el sexo se usa como un método estratégico de control disciplinario impuesto por la jerarquía :

Lo que quiero decir [...] es que una experiencia con unos muslitos tan reales como los tuyos, querida Eukene, podría cambiarnos al muchacho, piénsalo y que el chico que te entregamos borde nos lo devuelvas convertido en un hombrecito[...]

Los díscolos protagonistas de Comandos vascos y de $Y$ Dios... conviven con dos tipos de mujer antitéticos: la novia ausente y la compañera de comando. La primera es la mujer ideal, el amor adolescente, que simboliza la pureza de sentimientos, el amor no consumado y el mundo y el futuro sacrificado a la causa. A ella se le dedican pensamientos, en ella se ejercita el recuerdo y siempre está presente en los momentos de melancolía. Con la compañera de comando se forma una pareja de fortuna y sexo desde el principio -es el caso de Josechu en Y Dios...- o tras haber vencido el rechazo inicial por considerarla como amenaza para la mujer idealizada, caso de Mikel en Comandos vascos:

Nadie como Eukene para [ robar ] los coches. [...] me pregunto por qué me gusta estar con ella. También me pregunto por qué la rechazo[...] supongo que la explicación es sencilla. No he conocido mujer más peligrosa para Maitetxu y ésa [...] es la razón por la que mi rostro se cierra una y otra vez a la impertinencia continua de su cuerpo. 
El roce diario va creando tal grado de intimidad que la joven libera su palabra. De sí misma ofrece un retrato agridulce. Por un lado aparecen como mujeres muy masculinizadas, violentas y groseras, fracasadas, pero lúcidas, ante su presente :

Nos han convertido en mierda nuestros propios ideales. (Y Dios...) ... ésta no era la vida que buscaba[...] vivimos juntos pero estamos solos, nos queremos sin amor y moriremos llenos de odio (Comandos vascos)

Por otro, como niñas-mujeres que idealizan una feminidad convertida en terreno vedado : moda, vestido de novia , vida de pareja basada en la ternura... Entraron en la organización por seguir a un novio ${ }^{27}$ que se convirtió en un caído. Su recuerdo y su deseo de vengarlo les sirve como acicate en la acción y en su comportamiento sexual28:

Y a mí se me figura que lo busca en la cama, únicamente en la cama, y trata de vengarlo en la calle con la armónica dentro del brazo ( Y Dios ...)

Aunque en la vida clandestina se pueda llegar a cierto grado de intimidad, no hay que olvidar que existe también una elevada agresividad dirigida no sólo hacia el exterior sino también hacia los propios componentes del comando. El conflicto estalla entre estos seres violentos, desarraigados, aislados, sometidos a la presión de la disciplina interna y a la persecución policial ${ }^{29}$. Así, en las novelas estudiadas, la rivalidad entre los miembros de los comandos surge por celos (caso del típico triángulo amoroso o porque el líder manifieste preferencias por el protagonista en vez de por su fiel servidor) o por el sentimiento de inferioridad que experimenta uno de los miembros. En El mensajero, la violencia se ejerce en ambas direcciones, exterior e interior del comando, siguiendo la lógica de la emulación y respetando la jerarquía. Casimiro emula la crueldad de su jefe cuando viola a su compañera :

No se trata sólo de que estuviera alterado por la muerte de los dos policías; odiaba a Enrique en ese momento por haber golpeado así a un

\footnotetext{
27 En la vida real, la incorporación de mujeres a ETA se debe a sus lazos sentimentales, Vid. M. Antolín, op. cit. y F. Domínguez, op. cit.

28 «Los antropólogos han señalado la relevancia que la mujer adquiere en los actos funerarios de los etarras. En estos actos las madres y compañeras muestran su fuerza «indarra y simbolizan la fertilidad. La mujer se mantiene en su papel tradicional, como guardiana de la etxe «casa » representación de la tierra y fecundidad. Con el paso del tiempo no se resigna a ese papel pasivo [...] empiezan a imitar los aspectos más llamativos[...] de la conducta masculina.» $\mathrm{M}$. Antolín, op. cit., p. 62.

${ }^{29}$ F. Alonso-Fernández, op. cit., p. 263.
} 
hombre agonizante. Y descargó su furia contra Inés[...] enmascarando una violación con el desequilibrio que le había producido la violencia más descarnada...

Cuando Enrique muere torturado por la policía, Casimiro ocupa su lugar. Su nueva posición activa su autoestima y anula su complejo de inferioridad. Vengar a su predecesor en el cargo borrará el antiguo conflicto - lo idealiza tras su muerte-, animará su acción - masacre en una cafetería por la explosión de una bomba- y ayudará a recomponer la relación con su compañera violada, ajenos ya a las órdenes del partido.

En las novelas sobre etarras los conflictos surgen en el interior del grupo principalmente como consecuencia de la inasimilación de uno de sus miembros. Esto es así, porque el joven mantiene su individualidad.

A pesar de las circunstancias socioculturales o del adoctrinamiento ideológico, al que ha sido sometido un individuo en su ámbito social, el ingreso en una organización terrorista es una decisión libre, voluntaria e individual, a diferencia de la salida ${ }^{30}$. Por eso, en estas novelas que narran la peripecia vital del terrorista, se insiste tanto en la génesis. Lo que distingue a las novelas de terroristas de ultraizquierda de las de etarras es la función que desempeñan esos elementos de la génesis. En las historias con grupos de ultraizquierda, el lector tiene cumplida cuenta de los antecedentes y del universo mental del protagonista gracias a sus monólogos interiores y a la rememoración de su pasado mediante frecuentes analepsis. Paralelamente se narra en tercera persona y con focalización externa todas las actuaciones de terroristas y policías. En cambio, en las novelas de etarras, los antecedentes del protagonista y sus acciones son algo más que datos biográficos : aparecen como jalones de un viaje interior que le llevan a cuestionar la licitud del crimen como arma política. Esos jalones aparecen en una narración autobiográfica construída desde la perspectiva de un presente que rescata del pasado diferentes secuencias, encadenadas según la subjetividad del narrador, sin respeto de su cronología, a diferencia de lo que ocurre en la novela picaresca. El relato autobiográfico no sólo cohesiona los distintos episodios de la historia, no sólo permite que el lector bucee directamente en la intimidad del protagonista, sino que su coherencia surge de la justificación del acto mismo de la escritura. ¿Por qué cuentan su historia estos narradores? En Comandos vascos, la justificación es literaria. Esta novela se presenta como una « mise en abîme »o novela dentro de la novela. Un novelista escribe un relato inspirándose en hechos y personajes reales. En el epílogo, para subrayar que estamos ante un artificio literario, un personaje de la historia le proporciona los detalles sobre la muerte del

${ }^{30}$ F. Alonso-Fernández, op. cit., p. 264. 
protagonista y su interpretación del acontecimiento. Acto seguido, el novelista reelabora los datos literariamente. Salvo el primer capítulo y el último episodio, narrados en tercera persona, el terrorista cuenta su experiencia en primera persona. En otros relatos, unas veces, la justificación del acto de la escritura en primera persona es implícita : se trata de dejar constancia de un pasado, de cerrar un episodio vital para poder inaugurar una nueva vida ${ }^{31}$. Es el caso del protagonista de $Y$ Dios... quien, ya fuera de ETA, convive con su amor de adolescencia y con la amenaza del pasado. Otras veces la justificación es explícita. En la novela epistolar Grande Place, la mujer del ex-terrorista puntualiza :

Es importante para mí hacer este examen de conciencia[...] para poner un poco de orden, para conocer mejor lo que me ha sucedido.

Lo mismo ocurre en Una balleza convulsa, novela autobiográfica de estructura circular cuyo protagonista fue secuestrado por ETA. La escritura era un medio de supervivencia durante su cautiverio y después se convierte en recurso para dar testimonio del pasado y de su fortaleza presente :

Quiero dejar memoria de los días que no fueron, recuerdo del tiempo robado y del torbellino de emociones que agitó aquellas jornadas sin sol ni noche

Los elementos privilegiados en la génesis del terrorista son el ambiente familiar, la razón del ingreso y la socialización dentro el grupo. Analizaremos la figura de los padres en primer lugar. Se trata de una figura capital a la hora de explicar las motivaciones y de analizar la personalidad del terrorista. Como ponen de manifiesto los psicólogos, las relaciones conflictivas entre padre e hijo aparecen como una constante :

La mayor parte de los terroristas de un signo político y de otro están movidos por el sentimiento de odio y hostilidad contra la imagen y la figura del padre. Muchos de ellos están absorbidos por el afecto y la admiración hacia la figura materna ${ }^{32}$.

\footnotetext{
${ }^{31}$ Algunos miembros de ETA han atribuído a la escritura esta misma función. El caso más conocido es el de Dolores González Catarain, «Yoyes ». Sus familiares publicaron su diario y escritos en un libro titulado Yoyes, desde su ventana, Iruñea : Garrasi, E. Garmendia, 1987 . En su diario se puede leer : «Escribir es una necesidad, es un desahogo, casi un vómito, y pienso que también es arte[...] A mí me gustaría que mi escritura no fuera un desahogo[...] Mi angustia y mi desesperación puestas en un papel una y otra vez, ya estoy harta, ¿pero qué puedo hacer si cada vez mi crisis se hace más profunda y oscura ? » citado por M. Antolín, op. cit., p. 93-94.

${ }^{32}$ F. Alonso-Fernández, op. cit., p. 283.
} 
En Destruyan... la extacción social de los terroristas es dispar, en cambio el rencor a los progenitores, a la clase de origen, es idéntico. La española Teresa pertenece a una familia de clase media. Pese a vivir con su padre, ha roto toda comunicación con él y todos los vínculos afectivos. Lo desprecia por burgués y, por lo que simboliza, le roba para sustentar al comando. Su compañera alemana, Gudrun, se crió primero en un prostíbulo con una madre toxicómana, que no pudo impedir su violación a los once años, y en un orfelinato después. El jefe del comando, Anderson, creció en una familia de seres vencidos y humillados : su madre se prostituía en la postguerra alemana para alimentar a la familia mientras su padre los golpeaba. La acción revolucionaria es para él una terapia, un ajuste de cuentas con el propio pasado que a su vez sirve de justificación para el presente :

Se hace la revolución también para liberar de pesadillas la mente la acción y el peligro son en ocasiones el mejor antídoto la máscara que nos protege de los neurogases de la memoria pero la realidad incluye lo que hay dentro de nosotros algo inarmónico sin estructura racional ...

En las novelas de etarras la valoración de la figura del padre varía a medida que crecen las dudas del protagonista. Se ha señalado que el factor edípico se encuentra en la raíz de ETA, expresado como rebeldía de los jóvenes contra sus padres peneuvistas a los cuales dan lecciones con su furia revolucionaria ${ }^{33}$. Es indudable que este rasgo está presente en los relatos en los que aparece la primera generación de terroristas en una familia. En Grande Place, el padre que hay que vengar motiva la entrada en la organización. Este se convierte, años después, en el responsable del fracaso vital de los hijosterroristas. Se le acusa de ser un cobarde, por someterse a la comodidad económica que el proteccionismo del franquismo otorgaba a los vascos, un sembrador de odios con sus narraciones de penalidades pasadas, un instigador de venganzas, un creador de hijos asesinos :

Sin duda basta con narrar con aire misterioso a los propios hijos los propios mitos, miedos, ilusiones, sueños y frustraciones. Las cosas de la guerra[...]magnificada con sus historias e historietas. La noche de navidad, recordar las noches de navidad transcurridas en la cárcel, reservando un plato vacío para no olvidar la ausencia de un vasco preso, para que en el corazón del niño crezcan la sed de aventuras del Quijote y la necesidad de venganza de Hamlet.

${ }^{33}$ F. Alonso-Fernández, op. cit., p. 271. 
En Comandos vascos y en Y Dios... el descubrimiento del padre va en la dirección opuesta. En ambas novelas el protagonista, en su adolescencia, desprecia a su padre por su falta de implicación política. Su deseo de respeto a todos, de pacifismo, lo interpreta como un signo de cobardía y de menoscabo de su hombría. Pero al final del proceso, es decir, cuando le asalta la duda sobre la licitud del crimen, se reconcilia con él, asume sus valores. Así Josechu de $Y$ Dios... interpreta su aventura vital como un proceso de acercamiento a su difunto padre. Proceso que comienza con el desprecio inicial hacia él, continúa con la rebeldía materializada en su primer crimen y con la sustitución de su figura por la del jefe del comando, Papadoc - su reverso-, y finaliza con la identificación. El padre de Mikel de Comandos vascos se yergue en la contrafigura de todos los hombres que han rodeado a su hijo. Si al principio Mikel lo considera un cobarde $y$ un traidor -estaba a favor de la industrialización de las Vascongadas-, al final lo ve como un hombre sereno y en paz, un ser al que envidiar. El caso de Peter, en Gudari Gálvez, es el de la segunda generación de terroristas. El aspirante a terrorista, nieto de banquero nacionalista y huérfano de un etarra asesinado por los Gal, actúa llevado por el recuerdo mitificado del padre-héroe desconocido, el deseo de emular su destino y el odio instilado por la familia paterna.

La decisión de ingresar en una organización armada responde a diversas motivaciones. Por lo que respecta a estos relatos, los ultraizquierdistas militan en un partido que da la orden de pasar a la lucha armada. Orden que aceptan con mayor o menor emoción, pero que les es impuesta, es el caso de El mensajero, o de la cúpula de la organización alemana en el caso de Destruyan .... En las novelas de etarras la decisión es soberana, una auténtica elección vital. En Grande Place el protagonista masculino se impone a sí mismo el ingreso como el cumplimiento de un servicio militar con el que vengar las humillaciones referidas por su padre. El manejo de las armas es para él un « rito iniciático» . En Y Dios... el rito iniciático consistirá en el asesinato de un militar. De este modo Josechu prueba al grupo, al que su hermano pertenece, que es digno de ser admitido en él a fin de realizar sus sueños : convertirse en un héroe de carne y hueso. En Comandos vascos el crimen del protagonista para vengar la muerte de un amigo íntimo tiene mucho de rito iniciático, pero Mikel vive su entrada como algo angustioso. En primer lugar porque no sabe escapar a la presión que la banda ejerce sobre él y en segundo lugar como mal menor para escapar a la policía y al mundo de la delincuencia común.

El proceso de socialización tiene el mismo fin en los distintos tipos de comandos : la creación de un hombre nuevo, el homo revolucionarius. Para ello se opera en dos planos : el del comportamiento y el de la estucturación cognitiva. 
En cuanto al comportamiento, en algunos relatos, la exposición de normas es somera y general : cambio de personalidad, sometimiento a la autoridad del partido, entrenamiento en el robo de coches y en el tiro, respeto a las normas de seguridad, como en El mensajero. En cambio, en las novelas de etarras se detallan todos los aspectos que regulan la vida del miembro de comando, bien porque el nuevo, como en Comandos vascos, quiere sistematizarlos confeccionando un manual, bien porque el recuerdo va trayendo a la mente del terrorista angustiado las consignas vigentes, como en $Y$ Dios... Se regula el comportamiento en libertad -vestido, cortesía, gestos, vida de fingida normalidad, renuncia a la vida privada -, en la cárcel -aislamiento, lloros e invención de historias personales que ablanden a los jueces- y se impone una ética : no robar a la organización ${ }^{34}$. Este conjunto de normas recibe la denominación de «catecismo ». No sólo es una expresión del estatus que el nacionalismo ha alcanzado como religión de sustitución ${ }^{35}$ sino que nos remite al Catecismo revolucionario (1869), redactado por Netchaiev o por Bakounin, texto que definía una moral en la que la revolución sustituía a la idea de Dios, ponía las bases del sistema de organización de los grupos terroristas, esbozaba la estrategia con la que empujar al pueblo a la revuelta ${ }^{36}$ y perfilaba la psicología del terrorista. La personalidad del líder del comando que hemos analizado anteriormente parece inspirada por el ideal netchaieviano ${ }^{37}$. Estos principios han impregnado los movimientos revolucionarios posteriores cuyo catecismo es también alimento espiritual de nuestros terroristas de novela, así, deben leer las Actas tupamaras, los Temas militares de Engels, a Marighella :

El Mostachos, que lo único que había conseguido aprender del Minimanual de la guerrilla urbana, de Marighella , era aquello de que «la razón de ser del guerrillero urbano es la de apretar el gatillo de su fusil »

\footnotetext{
${ }^{34} \mathrm{Al}$ parecer, los robos han sido un problema disciplinario para ETA. Tras el asalto de bancos no se remitía el dinero a la jerarquía. Si el terrorista era toxicómano se quedaba con el dinero del comando. Vid. F. Domínguez, op. cit., p. 211 y sig..

35 La concepción del nacionalismo catalán como religión, y en consecuencia el léxico religioso, está muy presente en la novela-ensayo Extranjeros en su país.

${ }^{36}$ R. Gaucher, Les terroristes, Paris, Editions Albin Michel, 1965, pp. 16-17.

37 «El revolucionario es duro consigo mismo y debe serlo con los otros. Todas las emociones tiernas o afeminadas de connivencia, amistad, amor, gratitud e incluso de honor deben ser reprimidas en él por una pasión fría y terca por la causa revolucionaria. No hay más que una delicia para él, un único consuelo, una recompensa y una gratificación : el triunfo de la revolución. Día y noche no debe tener más que un único pensamiento, un único objetivo : la destrucción total. En la consecución fría e infatigable de ese objetivo, debe estar dispuesto a morir y a destruir con sus propias manos todo lo que pudiera impedírselo». G. Chaliand y A. Blin, op., cit., p. 523. (La traducción es nuestra).
} 
Para obtener la desconexión moral del individuo, éste debe cambiar su estuctura cognitiva. Tiene que adquirir una serie de creencias que conviertan en aceptable el acto de matar. Lo concebirá como medio inevitable con el que alcanzar nobles ideales ${ }^{38}$. En este proceso, el uso de un lenguaje deshinibidor, basado en eufemismos y en la jerga militar, es de primordial importancia. Le permite verse a sí mismo como un soldado que lucha contra un Estado opresor. El vocabulario se compone de términos corrientes cuya cotidianeidad sirve para banalizar la naturaleza de sus acciones y para ofrecer una denominación racional y legal a prácticas ilegales. De esta forma se refuerza la unidad del grupo con un discurso que reinterpreta la realidad social y la distingue de las categorías políticas, morales, éticas de la legalidad democrática ${ }^{39}$. En nuestros relatos, la jerga de la banda, que refuerza la verosimilitud de la narración ${ }^{40}$, permanece inalterada a pesar de las dudas que asaltan al protagonista y del cambio de perspectiva que supone la narración del pasado en primera persona, caso de Y Dios... Así, encontramos térmimos como acción, faena, trabajo por acto terrorista; impuesto revolucionario por extorsión; arresto por secuestro; indemnización, multa por rescate ; chicle por explosivo; cargarse, volar, ajusticiar, ejecutar, golpear por asesinar; pipa, armónica por pistola ; pedazos por cadáver ; amona por organización ; kaiola por piso franco ; patriota, gudari por terrorista o asesino; perros por fuerzas del orden. Es evidente que la animalización del enemigo facilita la distanciación necesaria para su supresión. Dado que los ojos de la víctima condensan la humanidad, las consignas sobre la gestión de la mirada están muy presentes en el proceso de aleccionamiento ${ }^{41}$. El tiro en la nuca tiene por objeto despersonalizar y deshumanizar a la víctima además de garantizar la eficacia :

No debes mirarlos una vez en el suelo, eso es importante, no debes pensar o, si lo haces, hazte a la idea de que disparas contra lobos (Comandos vascos)

La variedad de miradas muestran diversos tipos de terrorista. Estas corresponden a distintas fases en la evolución de su personalidad. El neófito mira y tiembla ante la víctima (caso de Mikel en Comandos vascos), el « profesional » no mira o lo hace sin experimentar sentimiento alguno (Gayola

\footnotetext{
38 J. Sanmartín, El terrorista : cómo es, cómo se hace, Barcelona, Ariel, 2005, p. 156.

39 X. Cretiez, op. cit., p. 217.

40 L. Veres, «El signo perverso : sobre lenguaje, terrorismo y práctica periodística », Revista latina de comunicación social, año $5^{\circ}, \mathrm{n}^{\circ} 52$. www.ull.es/publicaciones/latina/2002

${ }^{41}$ Es interesante el análisis de la mirada de las víctimas y de los asesinos en el genocidio ruandés. Vid. X. Cretiez, op. cit., p. 211.
} 
en $Y$ Dios...) , el enajenado disfruta mirando cómo muere su víctima (Papadoc en Y Dios...).

Junto con el lenguaje eufemístico, el joven se dota de nuevas certezas con las que reinterpreta la violencia o afianza su ideología anterior. La justificación primigénea es de orden sentimental: nace del rechazo del presente industrialización, emigración- y de la añoranza de un pasado rural idealizado ${ }^{42}$ :

Mi tierra está en peligro y para salvarla no valen con ella virtudes cívicas[...] los que la amamos hemos cogido las armas. ( Comancos vascos)

Después no sólo recibe consignas sobre la licitud del asesinato,
Matar es lícito para los que están dispuestos a morir (Comandos vascos)
Seguramente te han enseñado que matar es pecado, pero en la Guerra Revolucionaria todo es lícito (Y Dios...)
Para emprender una lucha revolucionaria no se pueden emplear métodos que no sean revolucionarios (El mensajero)

sino que éste se concibe como un deber moral de purificación : Matar es limpiar y purificar (Comandos vascos). Al mismo tiempo que se le desresponsabiliza - La amona es la que golpea, no tú (Comandos Vascos) - se le ofrece una justificación política de sus actos, según la cual la existencia de la banda y sus acciones corresponderían a un deseo popular, democrático :

Matamos [...] porque respetamos al pueblo que nos ha convertido en su brazo armado porque todo lo que el pueblo quiere está justificado y, si el pueblo quiere la independencia, es traidor quien le da la espalda (Comandos vascos)

Pero el considerarse como expresión de la voluntad popular se desvincula del sistema político, democracia parlamentaria, en el que viven :

La lucha nada tiene que ver con la democracia y no acabará mientras siga ocupado militarmente el país, oigo la voz de A. [...] con claridad mientras la mía se desvanece...(Comandos vascos)

La victimización, el considerarse a sí mismos como ejecutores la voluntad del pueblo, la noble grandeza de la causa y el discurso sobre la purificación étnica aparecen como ideas y prácticas constantes en todo

42 Sobre la raíz melancólica del nacionalismo vasco Vid. J. Juaristi, El bucle melancólico, Madrid, Espasa Calpe, 1997. 
nacionalismo 43 . Ideas que se usan tanto como corpus teórico con el que crear naciones ex-nihilo ${ }^{44}$ como retórica para desconectar moralmente a los terroristas. ETA, como grupo híbrido que es, además de seguir planteamientos nacionalistas, se apoya en los de la izquierda revolucionaria. Así para Carlos Marighella, el terrorismo, concebido como guerrilla urbana, es un medio cuyo objetivo es provocar una represión desmedida de las fuerzas de seguridad. Gracias a ella, el pueblo, en su desesperación, abrazaría la revolución ${ }^{45}$. Este principio está presente en Destruyan a Anderson, cuyo modelo es el grupo Baader-Meinhof y su teoría científico-revolucionaria, en las novelas de etarras y en El mensajero :

Esto es el abecé : si el partido inicia la lucha armada es para sacar a las masas de su actual nivel de conciencia[...] hay que forzar la situación. Nosotros servimos de espoleta para que el poder se encargue del resto ejercitando la represión.( El mensajero)

Las novelas analizadas muestran las diferentes justificaciones en las que el terrorismo se escuda. En primer lugar, cuando se considera que éste constituye la única manera de alcanzar la libertad a los ciudadanos privados de derechos. Es el caso de La noche española en donde un antiguo republicano español, exiliado en Francia, planea el magnicidio para acabar con el régimen franquista. Tomás se ve así mismo como un luchador de una lucha inconclusa : contra los nacionales, resistente contra los nazis que ocuparon Francia y, otra vez, resistente contra Franco. No olvidemos que el terrorismo se convirtió en un instrumento de resistencia durante la Segunda Guerra Mundial. Se trataba de un terrorismo de guerra con una técnica parcticular : la estategia de desgaste del enemigo $^{46}$. En segundo lugar, el terrorismo que se ejerce en nombre de un territorio y de una bandera para alcanzar un nuevo estado independiente del Estado opresor. Sería el caso de los movimientos y guerras de liberación nacional, teñidos de ideología marxista-leninista ${ }^{47}$. Estos se consideran en una

\footnotetext{
43 X. Cretiez, op. cit., p. 213.

$44_{«}$ [el nacionalismo] Cree ser un movimiento que defiende derechos de naciones previas, pero en realidad es un movimiento inventor-forjador de naciones. [...] El nacionalismo cree servir a naciones «primordiales », subsistentes por sí mismas, pero de hecho las crea. » F. J. Contreras Peláez, «Cinco tesis sobre el nacionalismo » Revista de estudios políticos, No 118, 2002, pp. 257-290.

45 G. Chaliand y A. Blin, op., cit., p. 253. Vid. El testimonio de Pío Moa, antiguo miembro del Grapo, en su blog de Libertad Digital del 1/06/06 : "Y nosotros no luchábamos contra la represión, sino que la exacerbábamos, de forma muy deliberada en el caso de la ETA, mediante la mecánica "acción-reacción-más acción": golpeando y ocultándonos a fin de atraer la represión sobre la gente común y provocar así su radicalización política. »

46 G. Chaliand y A. Blin, op., cit., p. 229.

47 F. Fanon, Les damnés de la terre, Paris, La découverte, 2003.
} 
situación de guerra análoga a la dada entre dos naciones soberanas ${ }^{48}$. ETA se inscribe gustosa en este contexto. El tercer tipo es el terrorismo practicado en democracia, cuyo objetivo es la destrucción de la democracia liberal y de sus instituciones. Las representaciones políticas que vehicula este terrorismo son de origen pre-moderno. Da a la soberanía democrática una figura antropomórfica, recupera la idea del tiranicidio y justifica la resistencia armada en nombre de un pueblo concreto, no definido por su igualdad ante la ley, sino por la desigualdad económica. Propone una concepción medieval de la sociedad en la que la clase social equivale a la idea de pueblo, según la concepción holista medieval. Su filosofía central es marxista -la democracia como ilusión formalpero encuentra en Lenin la justificación de la violencia y la idea del imperialismo que permite internacionalizar la lucha de clases ${ }^{49}$. La aversión al sistema democrático la experimentan tanto los terroristas de El mensajero el día del referendum de la constitución española de 1978 como los de Destruyan a Anderson, quienes, en plena guerra fría, planean un atentado en Madrid para desestabilizar las democracias occidentales. Anderson se recuerda como rebelde y disidente frente a los instructores de la izquierda clásica. Se presenta como superador del marxismo que acepta participar en el juego democrático. Para ello se forma como autodidacta leyendo a los primeros anarquistas. Su visión del mundo y su concepción del terrorismo debe mucho a los nihilistas y a teóricos como Herbert Marcuse y Jean-Paul Sartre en la visión pesismista de la naturaleza humana y en el culto a la violencia como fin en sí mismo ${ }^{50}$ :

El terrorismo como azote obligado practicado desde tiempos remotos por todos los que han gobernado y una conclusión los pueblos han sido sometidos por el terror[...] nada se respetará leyes principios morales humanismo vida y familia todo será barrido por el viento de la goma dos que es el nuevo viento divino el nuevo kamikace el terror es flor de putrefacción cuando la vida se renueva surge la bomba[...] la política se ha hecho ininteligible y solo la violencia puede clarificar el caos...

En las novelas de grupos de ultraizquierda los terroristas son de una pieza y perecen en la acción. En cambio, en las novelas de etarras, se muestra a un aprendiz con problemas de asimilación al grupo. Es decir, en ellos no ha

\footnotetext{
48 G. Chaliand y A. Blin, loc., cit., p. 229.

49 F. Furet, Terrorisme et démocratie, Paris, Librairie Arthème Fayard, 1985, pp. 7-33.

50 «For Marx viewed violence not as an end in itself, but a necessary means for achieving ultimate victory for the proletariat. Violence would be the necessary midwife of revolution, Marx believed, because the bourgeoisie would never finally give up its power without a fight.[...] Sartre transvalues and glorifies violence and terror as ends in the themselves, and sees violence as a constant duty and sel-fulfilment for the oppressed» P. Wilkinson op. cit., p.76.
} 
triunfado totalmente la desconexión moral a la que la banda les somete, pues experimentan empatía por sus víctimas. En Comandos vascos a Mikel le repugna matar al rector de la universidad porque simboliza la inteligencia, la cultura, valores en los que cree; Josechu de $Y$ Dios... conversa y mira a un joven militar que debiera ser su próxima víctima. Al pensarlo como ser humano, quebranta los principios operativos de la organización. Las dudas de naturaleza moral y religiosa 51 , los remordimientos, los sentimientos de culpabilidad - simbolizados a lo largo del texto por una gaviota- que le asaltan le hacen cuestionar la licitud del crimen :

Comprendí entonces que fuera cual fuese el pretexto, no podía matar a mi prójimo, porque hacerlo era destruir parte de la Divinidad. Supe también que si llegaba alguna vez al extremo de no poderme perdonar a mí mismo, buscaría mi perdón en el amor de Dios.

Acabará por modificar un atentado para salvar vidas, hecho por el que la organización le considerará «traidor a la causa». En Comandos vascos, el protagonista y Goti, un compañero, experimentan una mengua de fe en los ideales revolucionarios, pues se plantean el terrorismo como una cuestión vital que les interroga sobre el sentido de su vida y de su militancia. Las ensoñaciones heroicas ${ }^{52}$ de Goti se tambalean ante la rutina y la banalización del crimen, tras asesinar a dos personas que ni se defienden ni se indignan :

.. no necesitaba pensar [...] matar era algo grande. Hoy matar es bárbaro, me refiero matar a gente resignada que te levanta los ojos o los baja hacia la mesa con desprecio y resignación.[...] Morir no tiene importancia dice Goti-, todos los días muere gente. Lo que me pone nervioso es que, de tanto como sucede, no suceda nada grande.

Sus dudas convierten a Mikel en un sospechoso de cobardía y en un potencial traidor. Pero en vez de transgredir las leyes del grupo, optará por probar su sumisión. Se impondrá la tarea de cometer en solitario el crimen que más le repugna con el único objetivo: «ser como ellos ». A lo largo de su reflexión, la noción de cobardía evoluciona. Primero, es cobarde quien no defiende la tierra con armas, como sus padres, después quien no tiene agallas

${ }^{51}$ El encuentro con el sentimiento religioso no es mero producto de ficción. El etarra Philippe Sáez, Txistu, tomó los hábitos tras siete asesinatos (1978-79) y José luis Alvarez, Txelis, detenido el 29/3/92 se sintió tocado por la Gracia del Señor en la cárcel. Vid. F. Domínguez, op. cit., p. 169 y sig..

52 Sobre el deseo de grandeza y heroísmo que habita en los jóvenes etarras Vid. M. Alcedo Moneo, Militar en ETA, Donostia, Harenburn, 1997, pp. 84 y sig. 
para matar y por último quien, pese a sus dudas, no tiene el valor de dejar la organización ${ }^{53}$. De modo que, entre contradicciones, por cobardía, irá a asesinar al rector para probar a la organización que no es un "cobarde » al que le repugna matar. Pero la existencia de la duda le convierte en «traidor» potencial y el grupo reacciona planeando su asesinato. Estos dos relatos insisten sobre la irreversibilidad de la pertenencia a la organización terrorista. ETA consigue la cohesión del grupo y la extirpación de la disidencia mediante el miedo, la intimidación y el asesinato como principio de autoridad54. A consecuencia de estas prácticas, una nueva imagen del terrorista surge ante el lector : la del terrorista como víctima de sí mismo y de la organización. Aparece como un ser fracasado, escindido y perseguido. En Y Dios... Josechu será juzgado y condenado a morir, por los votos de su hermano y de su compañera, leales a la banda.

¿Cuáles son las las semejanzas existentes entre estos terroristas y los falsos: los infiltrados? Hemos de concluir que entre ellos existe cierta semejanza, pues los agentes dobles aparecen también como víctimas de la jerarquía militar que los ha modelado a su gusto y que destroza no sólo su personalidad sino sus vidas. En Kilómetro cero, Juan trabaja ilegalmente a sueldo de militares que desean venganza -eliminando al presidente del gobierno - tras el maltrato recibido por el escándalo de terrorismo de estado de los años ochenta, conocido como el Gal. Roberto le ayuda en la misión. Ambos, antiguos miembros de la lucha antiterrorista, son seres derrotados, desengañados, hostigados y amenazados por sus antiguos compañeros, como los terroristas anteriormente analizados. Se entregaron con entusiasmo juvenil y patriótico a su misión, pero cayeron en desgracia al convertirse en testigos incómodos para sus mandos. Denunciaron que el fracaso de sus misiones se debió a la incompetencia y cobardía de los responsables de las operaciones. La represalias fueron el ostracismo, la exclusión del cuerpo e incluso el intento de asesinato :

Inmediatamente me convertí en un apestado. De la noche a la mañana el héroe se convirtió en villano.[...] Anularon mi testimonio alegando desequilibrio mental [...] dijeron que estaba loco, vaya, y regresé a Madrid[...] solo y abandonado, hundido en la miseria y asustado porque ya no era ETA sino mis propios compañeros quienes podían pegarme dos tiros.

\footnotetext{
53 En La noche española la compañera de Tomás lo acusa de ser « cobarde » por querer continuar la lucha asesinando a Franco y por no adaptarse a la nueva situación, por no saber pasar de la juventud a la madurez.

${ }^{54}$ F. Domínguez, op. cit., p.287. El caso de Yoyes es paradigmático.
} 
La equiparación entre terroristas y miembros de las fuerzas de seguridad como víctimas de ellos mismos y de sus respectivas jerarquías aparece expresamente en boca del ex-terrorista Antxon en Una belleza convulsa :

- Una vez descubrimos que dos guardias civiles se habían introducido en los ambientes abertzaltes de Bayonne vestidos de paisano[...] Eran unos mandados, unos infelices como todos nosotros, pero les tendimos una trampa y les matamos.

La figura del ex-terrorista, capaz de tal equiparación desasosegante, merece un análisis más detenido. Los psicólogos insisten sobre la dificultad que encuentran los terroristas que abandonan las armas en experimentar inmediatamente sentimientos de culpa, remordimiento o arrepentimiento. Esos sentimientos aparecen años después, cuando se ha producido un proceso de maduración de la personalidad del terrorista, bien haya sido un idealista apasionado o bien un narcisista agrupado ${ }^{55}$. En los relatos sobre ETA, los exterroristas son personas ya maduras que han cambiado : contemplan su pasado con desapasionamiento, distancia y sin remordimiento. Pertenecen a las primeras generaciones de ETA y encarnan la historia de la organización con sus diferentes escisiones ${ }^{56}$. Se presentan como víctimas de sus circunstancias que tratan de reconducir sus vidas. Tanto Antxon de Una belleza... como el protagonista de Gande Place, ambos amnistiados, cambian radicalmente las armas por el arte : el primero es un galerista cínico y epicúreo y el segundo es un guía que desvela la belleza de la plaza de Bruselas y la convierte en metáfora del aporte armónico del pasado, antítesis de lo que ocurre en el País Vasco. En cambio Ramondegui de La costumbre de morir sigue con las armas, reconvertido, primero, en mercenario y, después, en guardaespaldas de un magnate vasco que colabora financieramente con el mundo nacionalista. Ramondegui elude su pasado, aunque le pasará factura. Se aferra a su presente, limitado al amor por su familia y a la lealtad a su jefe. Los primeros aceptan lúcidamente su pasado al mismo tiempo que defienden su evolución ideológica y su actual posicionamiento político. Antxon rememora sus atracos a bancos, vuelve sobre la geografía de su juventud, no olvida el dolor causado a sus semejantes y se explica, al igual que el ex-terrorista de Grande Place, como producto de su ambiente y circunstancias : el romanticismo adolescente, la educación de sus padres, la fascinación por el marxismo revolucionario, el odio a la dictadura. Legitima el terrorismo de la primera ETA como instrumento de lucha contra la

55 F. Alonso-Fernández, op. cit., p. 292.

${ }^{56}$ Vid. A. Elorza (dir.) ETA, une histoire, Paris, Denoël, 2002. 
dictadura y por la democracia 57 . Pero frente al pasado, contemplado como algo noble, se alza el presente abyecto que condena :

No me arrepiento de haber tomado aquella opción[...] Era una lucha que me parecía legítima[...] si hubiera sabido entonces lo que ahora sé, que en nuestro nombre se iban a cometer crímenes atroces[...] nunca habría ayudado a parir este monstruo, porque es una fiera imposible de domesticar.

En Destruyan a Anderson no aparece una ex-terrorista propiamente dicha sino una ex-revolucionaria del mayo del 68 francés. Maika se ha convertido en una célebre prostituta-empresaria que gestiona negocios del sector. Es un ser descreído, destruído, desencantado, decepcionado y sobre todo nihilista. No salva nada del pasado ni del presente. Rechaza el terrorismo -intenta convencer a Anderson de que abandone, aunque acabará ayudándolo-, pero su rechazo no nace de una reflexión sobre la falta de justificación moral y política de la violencia en las sociedades democráticas sino de su oposición radical a la democracia liberal y a todo poder :

Si me dijeras que tienes la posibilidad de cambiar algo, te diría que estás mintiendo. Eres un torpedo humano que quieres desintegrarte contra el barco, aunque sabes que el barco no se hundirá.[...] la Revolución era nuestro Dios. Ahora ha muerto, pero recuerda a Pascal : «Si no hay Dios, todo es absurdo ». La fatalidad nos ha engañado. Detrás de la barricada no estaba la playa porque no había nada.

La imagen del terrorista se completa si tomamos en cuenta la que los demás y las propias víctimas tienen de él. Se les suele asociar con enfermos mentales. Por ejemplo, en La trampa, el protagonista, que se refiere a ellos como « esa gente », los trata de locos, de psicópatas, de esquizofrénicos, de seres primitivos. En El atentado aparecen simplemente como gente que posee otra lógica. $\mathrm{Y}$ en Destruyan... se opone hasta el humor la visión esquemática y realista del comisario Valverde a la descripción psicologizante del profesor experto en terrorismo :

- Romanticismo y fanatismo al cincuenta por ciento. Con un par de cojones de vez en cuando. Tan simple como eso. [...]

57 A esa explicación-justificación del nacimiento del terrorismo de ETA en la dictadura se opone, por ejemplo, Jon Juaristi en La tribu atribulada, Madrid, Espasa-calpe, 2002, p.14 « El terrorismo no es un fenómeno aleatorio, una desviación demencial, una excrecencia perversa de la Tribu, sino la consecuencia práctica del nihilismo: su paso a la acción. El terrorismo ya está previsto en los textos aurorales de la Tribu, en los escritos canónicos del fundador. » 
- El terrorista es egocéntrico y tiene una actitud hipercrítica hacia el resto de sus semejantes porque considera haber sido tratado injustamente por la sociedad. Busca sobre todo autoafirmarse actuando. Fundir el Ego con el Superego. En el fondo todo terrorista es un panteísta. [...]

En cuanto a las víctimas es bien conocido que el terrorismo produce en ellas alteraciones psíquicas que evolucionan en cuatro etapas : la negación del hecho, las reacciones timéricas, la depresión traumática y la resolución del conflicto. El rasgo que caracteriza a las víctimas del terrorismo en España es el de la sublimación del odio y la venganza en el deseo de justicia ${ }^{58}$. En estas ficciones, las víctimas directas, pero sin relación personal con los terroristas, se encuentran en alguna de las fases señaladas y resuelven el conflicto reaccionando de dos formas: la aceptación resignada59, pero reclamando justicia, o la venganza. En Extranjeros en su país aparecen estas dos soluciones en la misma familia. Por un lado, el hermano vengativo, presentado como un loco, un poseso llevado por el odio, cuya idea es cometer a su vez un atentado haciendo explotar un camión cisterna lleno de gasolina. Es decir, se le caracteriza con los mismos adjetivos e imágenes con las que se suele describir al terrorista . Por otro, el razonable, el que justifica el terrorismo de ETA en la dictadura ${ }^{60}$, el que mediante la razón desautoriza a su hermano. Defiende el Estado de Derecho y la institución de la Justicia frente al todos contra todos en una espiral sin fin :

Si tu dolor se venga, se convertirá en acto criminal para otros que, a su vez, se sentirán legitimados para hacer lo propio. Y así, ellos serán para ti criminales y tú serás criminal para ellos. Al final se perderá el origen y sólo campará el estado de guerra, donde la muerte legalizará el comportamiento irracional de todos.

La víctima vengativa ha tenido más éxito en la ficción. Es un personaje complejo que da lugar a una reflexión sobre la similitud de los procesos por los que una persona, miembro de una organización terrorista o no, se convierte en asesino. $\mathrm{Y}$ en este punto existe un paralelismo entre víctima vengativa $\mathrm{y}$ terrorista, al mismo tiempo que una inversión de papeles: la víctima se convierte en verdugo y el terrorista en víctima. Pero queda intacta la pasión que anima a ambos: el odio. En Destruyan... aparece la figura del justiciero

58 F. Alonso-Fernández, op. cit., p. 297.

59 «Le vino a la memoria la cara de la madre, tan digna, en el funeral. Aquel padre, envuelto en lágrimas como un niño, acompañando el cadáver del hijo, sin poder terminar de creer que estaba muerto ». La trampa

60 Para un recuento comparaivo de las víctimas de ETA en la dictadura ( 46 víctimas mortales) y en democracia, Vid. http://www.angelfire.com/pq/terroristas/eta.htm 
solitario : un tipo duro, fuera del sistema, que hace el trabajo sucio a petición de los servicios secretos - usa la tortura para obtener información - y al que se opone una parte de la policía porque desaprueba sus métodos. Sorel se ha convertido en su apoyatura teórica ${ }^{61}$. Otra vez se trata de un ser destrozado, sin ataduras afectivas, con muy pocas convicciones. Entre ellas, que la violencia es el único método para erradicar el terrorismo y éste debe utilizarse al margen del Estado de Derecho. Actúa por venganza y rencor :

Si la felicidad del mundo [...] justificaba matar a su mujer, él pondría el mundo boca abajo con tal que locos de esa especie no hicieran feliz a nadie.

En La costumbre de morir, la venganza se planea como proyecto vital. Más que misión, es destino trágico. A ella ha consagrado su vida el hombre que de niño presenció el asesinato de su padre, guardia civil. La preparación técnica la encontró en el Colegio de Huérfanos, la motivación, en el odio cuidadosamente cultivado en el hogar :

Los veinte de agosto, nos reuníamos en casa con un demencial rito mortuorio, misa, visita al cementerio y comida con el retrato de mi padre y el tuyo presidiendo la mesa, rezábamos por la muerte del asesino y desde niño supe que yo sería el matador.

El papel de los padres en la transmisión del odio y en la instrumentalización de los hijos como brazo ejecutor es similar al que hemos analizado en el caso de los terroristas de organización. En el momento de la venganza, los papeles se invierten para que nada cambie. El ex-terrorista se encuentra fuera de la lógica de la violencia, la víctima vengativa dentro. Esta se asegura de que el paralelismo sea total : el día del aniversario de la muerte de su padre abate al ex-terrorista en presencia del hijo de éste. El vengador asume su futura muerte violenta como si se tratara de un ineludible tributo generacional que pagar a las pasiones humanas :

Jon me miró a los ojos, le comprendo y no le guardo rencor, es su deber, cuando tenga mis años me buscará y, donde quiera que me encuentre, me dará muerte.

${ }^{61}$ G. Sorel, Réflexions sur la violence (1908), Paris, Seuil, 1990. Jacques Julliard lamenta en el prefacio que este texto haya sido malinterpretado y usado como justificación del terrorismo tanto por la extrema derecha nacionalista como por la extrema izquierda revolucionaria. 
El engranaje del crimen se vuelve incontrolable en Matar para vivir. Tanto, que el asesino a sueldo del vengador decide matarlo para que cesen los encargos y para evitar ser chantajeado posteriormente. Es una historia inquietante sobre la manipulación y la instrumentalización del sentimiento de injusticia y sobre la perversión a la que da lugar una Justicia que no da satisfación. Estamos ante un conflicto entre legalidad y justicia, entre la Justicia y la justicia como concepto moral. El brillante policía que mata accidentalmente a un etarra en el momento de la detención es apartado del cuerpo. Su sentimiento de injusticia le autoriza a aceptar el encargo de un antiguo militar, que se presenta como víctima del terrorsimo. Su misión es asesinar al autor del atentado, liberado tras una corta condena. Después se le encarga atacarse a la red social que hace posible la supervivencia de la organización : abogada de etarras, librero-cobrador de extorsiones, clérigo nacionalista, periodista. Actúa sustituyéndose a la Justicia y burlándola, al mismo tiempo que experimenta un enorme placer intelectual en el diseño y ejecución del crimen perfecto.

La reacción de las víctimas que mantienen una relación personal con los terroristas y la visión que de ellos tienen es más compleja. Esta relación se da de manera prolongada durante un secuestro. Una belleza convulsa explora las estrategias de supervivencia que desarrolla un individuo encerrado en un zulo y las relaciones que establece con sus secuestradores. Dichas estrategias son de dos clases : la físicas, - necesidades fisiológicas, el ejercicio- y las mentales, a través del recuerdo autoimpuesto como disciplina, la introspección como liberación y su expresión en la escritura. El secuestrado se ve a sí mismo como un enterrado vivo, como un cadáver en su ataúd. Esta metáfora la convierte en alegoría : los secuestradores son sus demonios ${ }^{62}$ y su espacio es el de otra vida, la del infierno, donde cree expiar sus culpas: infidelidades amorosas, relaciones conflictivas con su padre, manifestaciones anti-ETA. A lo largo del secuestro irá creándose una relación de complicidad, que acabará en cierta dependencia afectiva entre él y uno de ellos. Los otros terroristas le parecen seres rudos, broncos, violentos, insensibles con los que la comunicación es imposible. En la realidad, se produce un reparto de papeles que tiene como objetivo la debilitación psicológica de la víctima y su identificación con los raptores $^{63}$. Aunque en esta novela no se puede hablar propiamente de síndrome de Estocolmo, sí se genera en el secuestrado una dependencia regresiva en la

${ }^{62}$ ¿ Un tributo literario a F. Dostoievski, Los demonios (1870-1872) aunque el autor no lo consigne en sus Préstamos?

63« Tenemos la impresión de que los terroristas, a medida que disponen de información acerca de estos síndromes procuran « cocinarlos » artificialmente haciendo una labor antiterapeútica, para fomentar entre sus rehenes la debilitación psicológica y el sentimiento de culpa, ya que la persona afectada por el síndrome de Estocolmo es más fácil de retener que una persona apresada en su plenitud física » F. Alonso-Fernández, op. cit., p. 306. 
que se combinan los sentimientos de terror, culpa y gratitud. Lo interesante de este relato es que también se producirá una cierta dependencia en el secuestrador. La víctima apreciará y agradecerá las conversaciones con «su demonio », escrutará su humor, su locuacidad y llegará a pensarlo como ser humano, no sólo como demonio, al imaginar sus deseos sexuales y la relación de éste con su propio padre. El raptor utiliza la comida, la palabra y el juego como elementos que modulan la intensidad de la relación. Así, le preparará platos que le gusten, conversará largamente con él y - climax del proceso- le propondrá jugar a las cartas. El juego y el azar establecen una falsa igualdad, aunque la jerarquía se mantiene con la pistola, que permite la derrota simbólica del secuestrador y el premio del rehén, consistente en la recuperación de su dignidad: la micción de pie en un auténtico retrete. Pero son la lectura y la escritura las que propician la intimidad y el encuentro de los dos seres. Para poder sobrevivir a su reclusión, el raptado escribe su autobiografía en un cuaderno amarillo que su raptor le arrebatará. Vive primero la sustración como un robo de la memoria y secuestro de su intimidad. Pero su prosa cautiva al raptor quien, para no renunciar a ella, propone un pacto de lectura : lo leerá cada vez que le gane a las cartas. Por ironía del destino, el escritor fracasado se ha convertido en autor deseado : ha encontrado un lector que recibe su creación como premio y por ella pelea. La lectura genera la palabra y así el raptor desvela su intimidad y sus heridas de hombre abandonado: «el amor les dura lo que el embarazo ", frase que, rememorándola permitirá al secuestrado, ya en libertad, identificarlo. Aunque raptor y raptado pueden intimar tumultuosamente en temas personales, hay una barrera que los separa y una consideración que los acerca. La barrera es el asesinato y el odio. Coinciden en considerar que lo diabólico, el mal absoluto, es el odio en la mirada de un niño. Para el periodista, un niño que repite las consignas de su padre: « ; ETA, mátalos! »; para el terrorista, la mirada del hijo de una víctima :

...le apunté a la cabeza y le disparé dos veces. El hombre se desplomó sobre la acera y el niño se quedó parado[...] en sus ojos me vi reflejado con total claridad: yo era el diablo que acabada de arrebatarle a su padre. ¿Te crees que si fui capaz de matar a un hombre delante de su hijo voy a tener el menor reparo en acabar contigo?

La mirada se convierte en el código de lectura de la persona. La del terrorista es una mirada amaestrada para matar, pero que deja ver también su humanidad recónditamente herida en forma de culpabilidad, o eso quisiera la víctima : 
La imagen del terrorista en la novela española actual

Había en ella una determinación terrible y también el brillo de la culpa. Sí lo había hecho. Y después había seguido viviendo. Día a día, muerto a muerto.

Cuando transcrurridos dos años de su liberación, el raptor le devuelve el cuaderno amarillo, el periodista quiere pensar que quizá su escritura haya servido para transformar a aquel ángel caído.

Aunque se insiste en la violencia física y mental que supone un secuestro, ninguna transformación se produce en las relaciones entre el industrial Lizarraga y sus secuestradores en Lectura insólita de El Capital. Los Abeles - Abelbost, Abelbi, Abelbat, Abeliru64_ reinterpretan la historia bíblica : Caín se corresponde con el malvado capitalista y Abel con el bondadoso marxista-terrorista. El odio personal y de clase, el deseo de venganza, están en el origen del secuestro. La fuerte personalidad del industrial y su superioridad intelectual eclipsa a los etarras, que acabarán leyendo El Capital por indicación suya. El secuestro se revela para el secuestrado como un reto más para su personalidad emprendedora y combativa. Estudia el carácter de sus raptores, sus contradicciones para aprovechar sus debilidades y fugarse ; incluso llega a la idea del crimen :

[...] tú eres el bueno blando, por sensato, y por eso te elegí, al duro, Abelbi, se le tiene miedo pero se le respeta, por si acaso, por eso procuro ser duro, si eres blando te comen las moscas[...] por eso te ha tocado, en la muñeca un tajo para desarmarte y si resistes y fallo peor para ti, donde pueda, empuñaré la pistola...

Su fuerza es tal que desestabiliza a los secuestradores cuando, siguiendo su propia ideología, anuncia que cerrará la fábrica por jubilación. Más que una reflexión sobre el terrorismo y sus métodos, esta ficción retrata los distintos sectores sociales que cohabitan con el empresariado paternalista vasco.

Tanto las víctimas con relación directa con los terroristas como las que no la tienen oscilan entre la superación del trauma y la venganza. En este último caso, aparecen doblemente como víctimas: víctimas de la agresión terrorista y víctimas de su proyecto de venganza individual. Para llevarlo a cabo desarrollan comportamientos similares a los de los terroristas. Difieren de ellos en que su objetivo es meramente personal. Pero la venganza no restaura en absoluto la justicia buscada.

64 Sobre la ocultación de la identidad de los alias y apodos, su función exculpatoria, su papel propagandístico, su significación mítica, Vid. L. Veres, « Sobre el nombre propio : Alias y apodos en las noticias de terrorismo », Interlinguística, $\mathrm{N}^{\circ} 14,2003$, pp. 1043-1052. 
Para concluir, señalaremos que estos diecisiete relatos dan buena cuenta de los mecanismos sociales y psicológicos que producen terroristas, esto es, sujetos moralmente desconectados. Ofrecen en su conjunto una variada tipología que abarca desde el terrorismo de fines del S. XIX hasta el actual. El terrorista, hombre o mujer, aparece como un ser aislado, destruído, que se encuentra en un camino sin retorno, sometido a la organización, abocado a la muerte o a practicar la violencia como fin en sí mismo. Algunos son seres moralmente escindidos, en lucha íntima, entre la acción asesina y la reflexión sobre la licitud y el sentido del crimen político. Paradójicamente, la duda o la culpabilidad los humaniza y agranda su fracaso vital. Esta íntima disidencia acentúa su imagen de víctima del terror y de la jerarquía a la que sirve. Coinciden estos relatos en presentar la violencia de unos y otros como una trágica espiral cuyos motores son el odio y la venganza, cultivados a veces en el seno de la familia. De ahí que el mal absoluto sea matar ante el hijo. Cabe destacar el papel eminente que ocupan la lectura y la escritura. En general, la primera responde al adoctrinamiento y la segunda hace oficio de liberadora. Ambas son las aliadas de la introspección y de la agonía de estos terroristas de novela un tanto alejados de los terroristas de catecismo revolucionario. 